\title{
The heat transfer model for VGF technique with skull layer for halide crystal growth
}

\author{
V.I.Taranyuk, A.V.Gektin, A.V.Kolesnikov, V.V.Kalaev* \\ Institute for Scintillation Materials, STC "Institute for Single \\ Crystals"National Academy of Sciences of Ukraine, \\ 60 Lenin Ave., 61001 Kharkiv, Ukraine \\ "Sof-Impact Ltd., 29 Engels Ave., P.O. Box 83, \\ 194156 St. Peterburg, Russia
}

Received January 15, 2014

\begin{abstract}
The work is devoted to the investigation of the key parameters for reproducible skull technique of $\mathrm{Nal}$ based crystals. Combination of math simulation (CGSim software) with experimental measurements of the temperature distribution during the raw material heating, melting stage and later crystallization gave not only approval of the methodology but allowed to grow scintillation crystal with the same performance as typical for single crystals. The obtained results are applicable for the skull layer thickness minimization, melting and crystallization stages verification and estimation of the gradient for proper convection and crystal homogenization. As result the medium size $\left(250 \times 180 \times 45 \mathrm{~mm}^{3}\right) \mathrm{Nal}$ crystals were obtained.
\end{abstract}

Рассмотрены технологические параметры процесса выращивания кристаллов на основе $\mathrm{Nal}$ гарнисажным методом. Комбинирование математического моделирования, с использованием программного пакета CGSim, и экспериментальных измерений распределения температуры при нагреве сырья, плавлении и кристаллизации дали не только подтверждение методологии, но и позволили получать сцинтилляционные кристаллы с характеристиками, аналогичными для монокристаллов. Полученные результаты применимы для минимизации толщины гарнисажного слоя, определения этапов плавления и кристаллизации и оценки градиентов обуславливающих, наличие конвекции приводящей к гомогенизации кристалла. Получены кристаллы $\mathrm{Nal}$ размером $250 \times 180 \times 45 \mathrm{~mm}^{3}$.

Модель теплообміну при вирощуванні галоїдних кристалів гарнісажним методом. В.І.Таранюк, О.В.Гектін, А.В.Колесніков, В.В.Калаєв.

Розглянуто технологічні параметри процесу вирощування кристалів на основі Nal гарнісажним методом. Комбінування математичного моделювання, з використанням програмного пакета CGSim, і експериментальних вимірювань розподілу температури при нагріванні сировини, плавленні і кристалізації дали не тільки підтвердження методології, а й дозволили отримувати сцинтиляційні кристали з характеристиками аналогічними для монокристалів. Отримані результати можуть бути застосовані для мінімізації товщини гарнісажного шару, визначення етапів плавлення і кристалізації і оцінки градієнтів, які обумовлюють наявність конвекції, що призводить до гомогенізації кристала. Отримано кристали $\mathrm{Nal}$ розміром $250 \times 180 \times 45 \mathrm{~mm}^{3}$.

\section{Introduction}

Last years the skull technique was developed for different alkali halide crystal growth [1]. It was shown that this tech- nique is applicable both for the laboratory samples [2] and for the medium size samples $\left(250 \times 180 \times 45 \mathrm{~mm}^{3} \mathrm{Nal}\right.$ based crystals $)$ [3]. Relatively simple set up construction 
and absence of platinum crucible make this method attractive for the further development. The similar performance of the poly and single crystalline scintillation detectors [4] allows to look to this technique as an alternative for conventional Bridgeman and CZ technologies [5, 6] and claim for the reproducible conditions and stable technology development.

The key elements of such developments are optimal thermal conditions, reasonable convection for uniform activator distribution along the ingot and minimal thickness of the skull layer that are necessary for the high yield of the crystalline media. These parameters could be justified by the combination of growth condition simulations with a proper experimental verification of such type modeling.

This work was developed to such studies for the Nal based polycrystals grown by VGF (Vertical Gradient Freeze) technique with the skull layer.

\section{Experimental}

Multi parameter growth procedure does not allow to check and justify all variations of the growth conditions and claims for preliminary simulation of the process flow. Preliminary modeling of optimal parameters allows to minimize an experimental part of the study in favor of the optimal technology development. This is why we considered the modeling and experimental results for the Nal base crystal growth.

\subsection{Modelding}

CGSim [7] software has been chosen for modeling of the heat and mass transfer during the raw material melting and crystallization. Scheme of the modeled set-up is shown in Fig. 1. Geometrical sizes were selected the same as in experimental skull growth furnace.

The software allows to simulate convection on the melt using the Navier-Stokes equations in the Boussinesq approximation [8]. LES (Large Eddy Simulation) model was used for the melt turbulence modelling. An original model based on a combination of the ray-tracing and discrete ordinate approach [9, 10] was applied to simulate radiative heat transfer in semitransparent media.

All simulations were carried out for non steady process. The linear law for the temperature increase was used for the raw material heating and for the temperature decrease during crystallization stage. It was

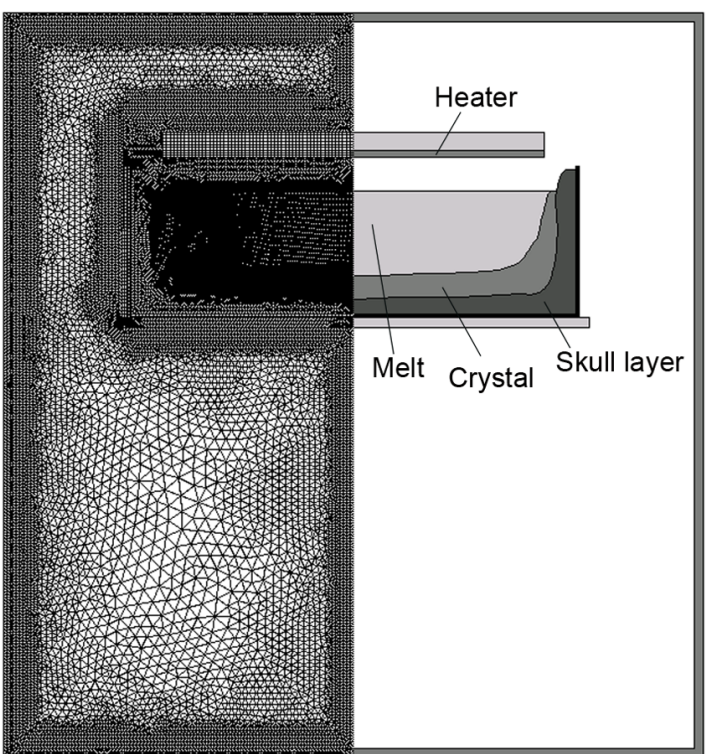

Fig. 1. Set-up scheme that used for CGSim simulation with mesh.

possible to record the melt-crystal interface shape, temperature distribution along the whole crucible, convection flow in the melt and mass crystallisation rate.

Parameters for the simulation are shown in Table 1. Some skull layer parameters (heat conduction coefficient, the layer absorption and so on) were estimated from experimental measurements made in this study. It was supposed that temperature at the set-up surface (water cooling cover) corresponds to the room temperature $(300 \mathrm{~K})$.

\subsection{Experiment}

Experimental studies were directed to the control of the temperature fields (horizontal and vertical gradients inside the crucible) during main stages of the crystal growth (melting and crystallization).

Skull technique equipment was similar to [1] and allowed to grow $250 \times 180 \times 45 \mathrm{~mm}^{3}$ in the 50 liter vacuum chamber. Detailed description of the experimental procedure was described in [11]. Five thermocouples were used for the temperature control inside the melt zone and an extra two ones - for the temperature measurement under the crucible bottom and near the heater. A map of the thermocouple locations is presented in Fig. 2. Four thermocouples were distributed along the central axis and an extra one was removed to the $50 \mathrm{~mm}$ from the central axis.

Temperature record accuracy does not exceed $1 \mathrm{~K}$ during the whole crystal growth cycle. 
V.I.Taranyuk et al. / The heat transfer model for...

Table 1. Nal thermophysical properties used in the furnace control

\begin{tabular}{|c|c|c|}
\hline Property & Value & Source \\
\hline Melting point, $\mathrm{K}$ & 934 & [12] \\
\hline Solidification heat, $\mathrm{J} / \mathrm{kg}$ & 160000 & [12] \\
\hline Dynamic viscosity, $\mathrm{mPa} \cdot \mathrm{s}$ & 1.4 & {$[13]$} \\
\hline \multicolumn{3}{|c|}{ Skull layer } \\
\hline Absorption coefficient, $\mathrm{cm}^{-1}$ & 0.2 & This work \\
\hline Thermal conductivity, $\mathrm{W} /(\mathrm{m} \cdot \mathrm{K})$ & 0.7 & This work \\
\hline Density, $\mathrm{kg} / \mathrm{m}^{3}$ & 2460 & This work \\
\hline \multicolumn{3}{|c|}{ Melt } \\
\hline Thermal conductivity, $\mathrm{W} /(\mathrm{m} \cdot \mathrm{K})$ & 0.234 & {$[12]$} \\
\hline Specific heat, J/(kg.K) & 447 & {$[12]$} \\
\hline Density, $\mathrm{kg} / \mathrm{m}^{3}$ & $3627.4-0.9491 \cdot T$ & {$[13]$} \\
\hline Absorption coefficient, $\mathrm{cm}^{-1}$ & $5 \cdot 10^{-4}$ & {$[14]$} \\
\hline Surface tension, $\mathrm{N} / \mathrm{m}$ & $0.4337-0.793 \cdot 10^{-3} T+0.437 \cdot 10^{-6} T^{2}$ & {$[15]$} \\
\hline \multicolumn{3}{|c|}{ Crystal } \\
\hline Thermal conductivity, $\mathrm{W} /(\mathrm{m} \cdot \mathrm{K})$ & 3.47 & {$[16]$} \\
\hline Specific heat, J/(kg.K) & 432 & [17] \\
\hline Density, $\mathrm{kg} / \mathrm{m}^{3}$ & 3655 & {$[18]$} \\
\hline Absorption coefficient, $\mathrm{cm}^{-1}$ & $5 \cdot 10^{-4}$ & [19] \\
\hline
\end{tabular}

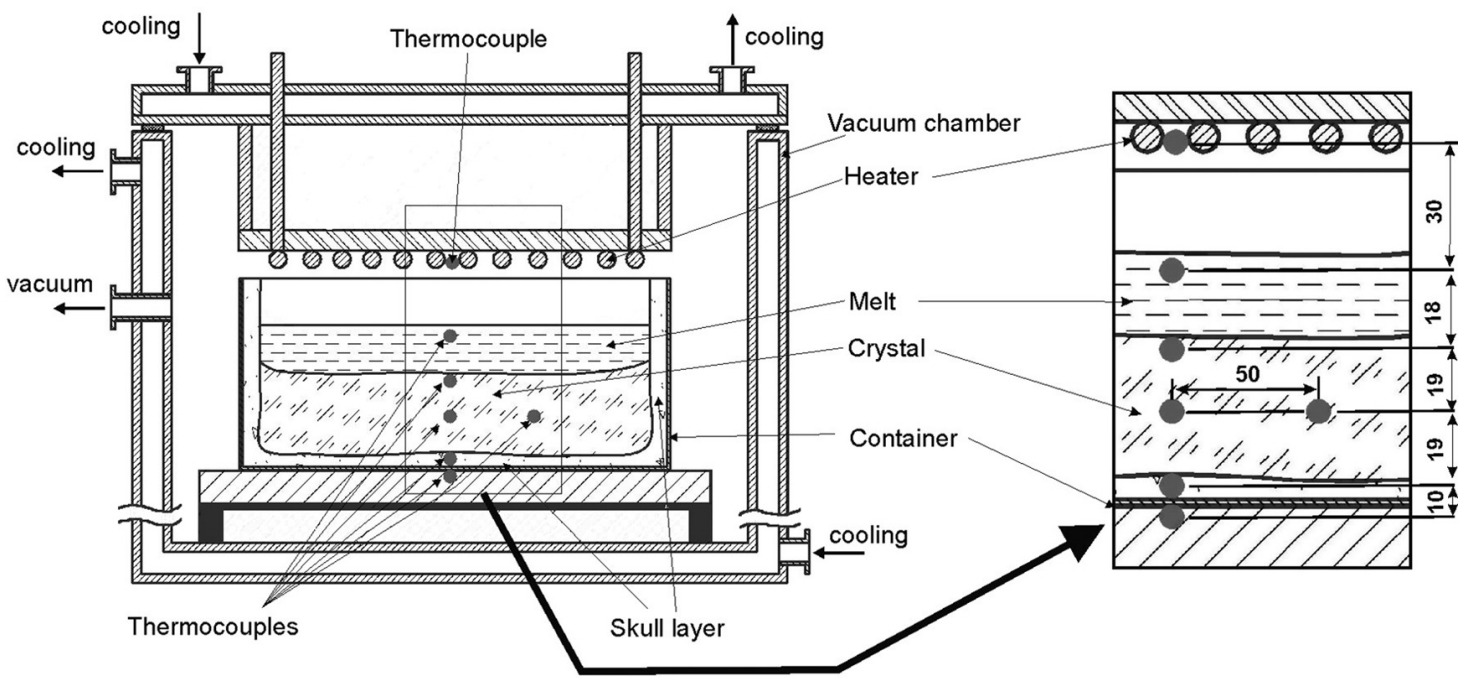

Fig. 2. Scheme of the skull method experimental set-up (left) and the thermocouple map (right).

\section{Results}

The main result of the process simulation is shown in Fig. 3 where the temperature distribution during the raw material melting (left diagram) and crystallization (right diagram) are presented. Table 2 demonstrates the modelling and experimental data to confirm a good correspondence between the modelling and practice in general.

In particular we have to note some results which are important for the stable growth process. The first is the big difference of temperature gradients in the skull layer. The maximal gradient can reach $210 \mathrm{~K} / \mathrm{cm}$. This is an important issue for the leakage protection. There were no traces 
V.I.Taranyuk et al. / The heat transfer model for...

Table 2. Simulated and experimental data of the temperature gradients

\begin{tabular}{|c|c|c|c|c|}
\hline & \multicolumn{2}{|c|}{ Vertical gradient, $\mathrm{K} / \mathrm{cm}$} & \multicolumn{2}{|c|}{ Horizontal gradient, $\mathrm{K} / \mathrm{cm}$} \\
\hline & Simulation & Experiment & Simulation & Experiment \\
\hline $\begin{array}{l}\text { Skull layer } \\
\text { (at minimal thickness }-10 \mathrm{~mm} \text { ) }\end{array}$ & 210 & 203 & $2-6$ & - \\
\hline Melt & $0.3-1$ & 1 & 0.05 & 0.2 \\
\hline Crystal (during crystallization) & 6.5 & 9 & 0.4 & $2.1-2.3$ \\
\hline
\end{tabular}
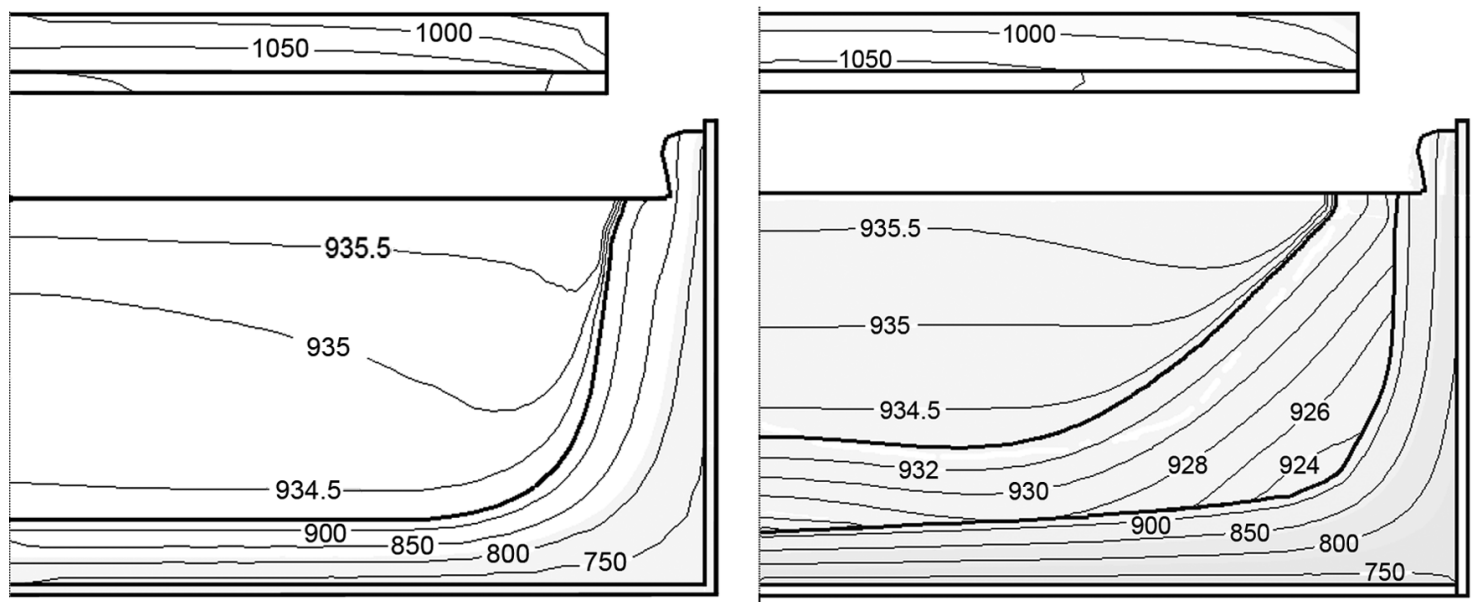

Fig. 3. Temperature distribution at the melting stage (left) and crystallization (right).

of the leakage during the crystal growth. The second is small gradient in the melt. This value is between $0.3-1.0 \mathrm{~K} / \mathrm{cm}$. In the crystal at the beginning of the growth this value is about $6.5 \mathrm{~K} / \mathrm{cm}$ and increase up to $21 \mathrm{~K} / \mathrm{cm}$ to the end of crystallization.

Regarding the gradient distribution through the ingot (horizontal gradient) in general it is necessary to note the following. The lowest gradient $(0.05 \mathrm{~K} / \mathrm{cm})$ in the melt central part was shown at the beginning with the trend to decrease up to $0.001 \mathrm{~K} / \mathrm{cm}$ in the crystallization process. At the same time the gradient rise up with removal from the center to the walls and can reach $7 \mathrm{~K} / \mathrm{cm}$ near the upper part of the melt-skull layer interface.

Another important data were obtained for the convection estimation. Fig. 4 demonstrates the general simulation of the melt convection distribution. The maximal flow speed is typical for the marginal areas of crystallization form. In this area the convection speed can reach $1.8 \mathrm{~mm} / \mathrm{s}$. Near the free surface this value decreases up to $0.15 \mathrm{~mm} / \mathrm{s}$ in the central part and $0.8 \mathrm{~mm} / \mathrm{s}$ near the edges. It correlates with the temperature field changes from the center to the edge area.

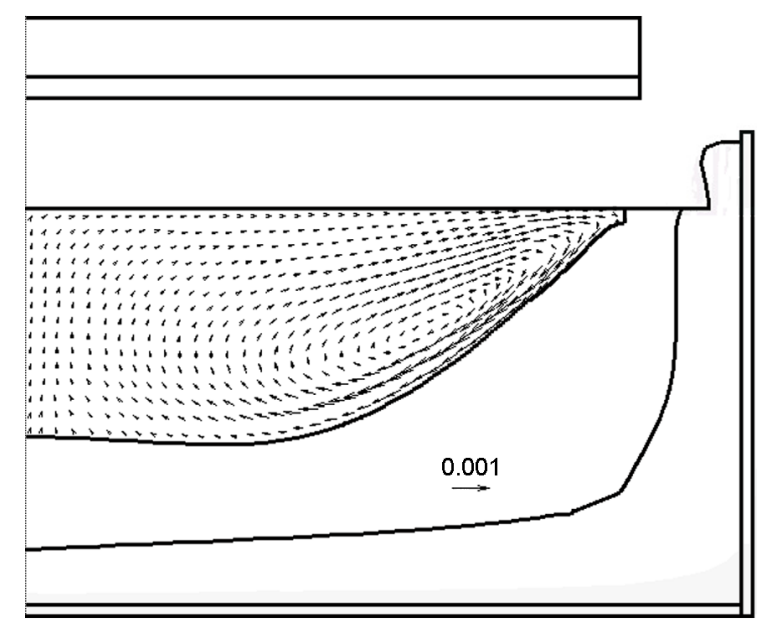

Fig. 4. Flow pattern in the melt during crystallisation stage.

It should be noted that experimental data are limited due to the minimal amount of the thermocouples inside the furnace. Increase of the thermocouple amount should deteriorate the temperature distribution. But anyway Table 2 demonstrates a good correspondence between the modeling and experiment for the vertical direction. The data for horizontal gradients do not coincide so closely. It could be explained by the too small values of the gradients and the lack of ability of more precise experiments. 
The general resume regarding comparison of the modelling and experimental data allows to conclude that the both approaches allows to make predictable and reproducible skull growth procedure.

\section{Discussion}

\subsection{Skull layer optimization}

This parameter is critical for the skull growth development. An optimal thickness of the layer should protect a crucible from the melt leakage and to minimize the powder losses for this layer creation. The skull layer absorbs about $80 \%$ of the radiative heat flow due to the opacity. This is a reason for the large temperature gradient inside the layer. So the layer thickness has to correspond to local gradient. Earlier, the state-of-the-art for the skull layer creation during the crystal growth allowed to reach the minimal $15 \mathrm{~mm}$ thick layer. The simulation shows that thickness decrease to $10 \mathrm{~mm}$ claims for at least $60 \mathrm{~K}$ temperature increase. The minimal layer thickness of 7$10 \mathrm{~mm}$ could be obtained if the crucible bottom temperature would be about $130 \mathrm{~K}$ less than the Nal melting point.

\subsection{Melting control}

The lack of the visual control for the raw material melting and later crystallization does not allow to fix the beginning and end of each stage of the process. The simulation shows that it is not necessary and it is possible to verify these changes from the control of the temperature distribution inside the crucible. These stages change have to be verified by the change of the bottom control thermocouple record only. At the heating beginning the heater temperature increase leads to linear increase of the bottom temperature. But after start of the melting the bottom thermocouple temperature increases sharply. For the crystallization stage it is observed the same effect. The bottom thermocouple temperature is decreased but when the crystallization end the decrease rate is lowered. The simulation data for these cases correspond to the experimental results described before [11]. So, this is an extra confirmation of the correspondence of the experimental and simulation data.

\subsection{The melt convection in skull growth process}

One of the most important aspects of the technology development is the melt convection rate that has to provide conditions for the uniform crystal itself and uniform activator distribution in particular. Absence in the furnace of any movable/rotates parts excludes an ability to maintain a proper level of convection and leaves for this goal thermal gradients in the melt only. Upper mounted main heater allows to sustain the permanent gradient in the melt, i.e. the upper levels of the melt are always overheated regarding the bottom ones. So, the gradients optimization has to be done in accordance with this claim too.

Fig. 3 demonstrates temperature decrease from the crucible center to periphery and proper surface tension changes (see Table 1) can make condition for the Marangoni convection. The melt flow is directed from the center and can reach $1.8 \mathrm{~mm} / \mathrm{s}$. Scintillation detectors made from skull grown ingot possess with the same performance as conventional single crystalline detectors [3] that confirms the uniform activator (Tl) distribution. This fact allows to conclude that convection level homogenizes an activator during the growth process. Another result can confirm this conclusion too. In [1] the activator was introduced in the raw material in one part of the crucible at the beginning of the growth cycle but at the end of the growth it was uniformly distributed through the whole ingot.

\section{Conclusions}

Finally, we have to conclude that CGSim [7] software is an efficient instrument for modelling of different stages and processes in the VGF skull technique of $\mathrm{Nal}$ crystal growth. High level of correlation between the modelling and experimental data proves this approach in general and demonstrates the ability to use the software for the growth parameters optimization. Three main problems which are typical for the skull technique - skull layer thickness minimization, melting and crystallization verification and estimation of the gradient for proper convection and crystal homogenization - could be solved with minimal amount of experimental efforts.

It should be noted also that combination of the modelling and experimental measurements of temperature fields during the growth demonstrate the ability to develop the reproducible technology of skull technique on favor of medium size $\mathrm{Nal}$ and $\mathrm{Nal}(\mathrm{Tl})$ polycrystal growth. 


\section{References}

1. V.Taranyuk, A.Gektin, I.Kisil et al., J.Cryst. Growth, 318, 820 (2010).

2. V.Taranyuk, A.Gektin, N.Shiran et al., $J$. Cryst. Growth, 380, 205 (2013).

3. I.I.Kisil, V.I.Taranyuk, S.V.Yaroslavkin, Functional Materials, 15, 600 (2008).

4. V.V.Shlyakhturov, A.V.Gektin, A.Yu.Boyarintsev et al., Functional Materials, 4, 20 (2013).

5. Kyoshiro Imagawa, Horiba Technical Reports, Readout, v.9, 98.

6. A.Gektin, B.Zaslavsky, Crystal Growth Technology, John Wiley \& Sons, Ltd, Chichester (2003).

7. http://www.str-soft.com/products/CGSim/

8. V.V.Kalaev, A.I.Zhmakin, E.M.Smirnov, $J$. Turbulence, 3, 1 (2002).

9. V.V.Vasilyev, V.I.Goriletsky, O.Ts.Sidletskiy et al., Opt.Mater., 30, 109 (2007).

10. S.E.Demina, E.N.Bystrova, M.A.Lukanina et al., Opt. Mater., 30, 62 (2007).
11. V.Taranyuk, A.Gektin, I.Kisil et al., J.Cryst. Growth, 360, 95 (2012).

12. V.D.Golyshev, M.A.Gonik, High Temp.-High Pres., 2, 677 (1992).

13. G.J.Janz, F.W.Dampier, G.R.Lakshminarayanan et al., NSRDS-NBS 15, US Government Printing Office, Washington (1968).

14. V.D.Golishev, in: Book of Abstr. of 6-th Intern. Conf., Obninsk: GNC RF-FI (2005), v.4, p.783.

15. G.J.Janz NSRDS-NBS 28, US Government Printing Office, Washington (1969).

16. http://www.hilger-crystals.co.uk/properties.a sp? material $=13$

17. L.V.Gurvich, I.V.Veic, V.A.Medvedev et al., in: Thermodynamic Properties Individual Substance, Nauka, Moscow (1981) [in Russian].

18. M.Globus, B.Grinyov, Jong Kyung Kim, in: Inorganic Scintillators for Modern and Traditional Applications, Kharkiv (2005).

19. E.M.Dianov, A.I.Mitichkin, A.N.Panova et al., Quant. Electron., 1345 (1980). 